\title{
Immunostimulation-Mediated Anti-tumor Activity of Bamboo (Sasa senanensis) Leaf Extracts Obtained Under 'Vigorous' Condition
}

\author{
Takahiro Seki ${ }^{1}$, Kenji Kida ${ }^{1}$ and Hiroshi Maeda ${ }^{2,3,4}$ \\ ${ }^{1}$ Graduate School of Science and Technology, ${ }^{2}$ Department of Microbiology, School of Medicine, Kumamoto \\ University, ${ }^{3}$ BioDynamics Research Laboratory, Regional Cooperative Research Center of Kumamoto \\ University and ${ }^{4}$ Laboratory of Microbiology and Oncology, Faculty of Pharmaceutical Sciences, Sojo University, \\ Kumamoto, Japan
}

Traditional Japanese medicine uses the leaves of Kumaizasa bamboo extracted in hot water at $100^{\circ} \mathrm{C}$. For this study, we developed a new, 'vigorous' extraction method involving steps at 100 , 121 and $196^{\circ} \mathrm{C}$. This procedure not only yielded greater amounts of extract but also with significant increase in immunostimulating activity, which induces activation of human natural killer (NK) cells, macrophages and potent induction of IL-2, IL-12 and IFN- $\gamma$ in tumor bearing mice. The efficacy of the extract to facilitate phagocytosis and nitric oxide production by mouse peritoneal macrophages was determined and compared with that of 1,3- $\beta$-glucan. Anti-tumor activity was evaluated in vivo in several mouse tumor models (S-180, C38 and Meth-A). Oral administration of the extracts was carried out when tumor reached size of approximately $6 \mathrm{~mm}$ at concentrations of $0.05 \%$ or higher. The extracts significantly suppressed tumor growth in S-180 and C38 tumor models. Overall survival was significantly prolonged in the treatment group than that of control. Activation of macrophages and NK cells by the extracts suggests that the anti-tumor efficacy of the extract is mediated by immunopotentiation. The extracts resolved into three major fractions (F-I, F-II and F-III) in Sephadex gel chromatography. Fraction F-I consists of 1,3- $\beta$-glucan and stimulated both macrophages and NK cells suggesting that it may be the primary immunopotentiating factor in suppressing cancer. Fraction F-III has potent free radical scavenging effects and may play an important role in cancer prevention. These results warrant further translation and clinical investigations.

Keywords: high-temperature/high-pressure extraction - multistep extraction - NK cell activation - macrophage activation - 1,3- $\beta$-glucan

\section{Introduction}

One of the causal factors of tumor progression is suppression of immune functions. Restoring the immune competence can be one of the primary strategies of active immunotherapy. Polysaccharides from mushrooms or microbial cell-wall components were shown to be efficient

For reprints and all correspondence: Professor Hiroshi Maeda, Laboratory of Microbiology and Oncology, Faculty of Pharmaceutical Sciences, Sojo University, 22-1, Ikeda 4-chome, Kumamoto 860-0082, Japan. Tel/Fax: +81-96-326-4114; E-mail: hirmaeda@ph.sojo-u.ac.jp immunostimulating agents. The extracts of the Kumaizasa bamboo leaves were shown to be anti-inflammatory (1). We hypothesized that the extracts may also posses immunopotentiating function. To test the hypothesis, we have undertaken this investigation. The first objective was to evaluate the anti-tumor activity and the immunopotentiating efficacy of the bamboo extracts under vigorous conditions. The second objective is to identify the active principle in the extracts that is associated with immunopotentiation. The results of this investigation encourage 
undertaking further translational and clinical investigation with the bamboo leaf extracts for treatment of cancer.

\section{Methods}

\section{Materials}

Interleukin (IL)-2, IL-12 and interferon- $\gamma$ (IFN- $\gamma$ ) were purchased from Pierce Biotechnology (Rockford, IL). 1,3-3-Glucan from Lentinula edodes (MW $10000-40000$ ), 1,3- $\beta$-glucanase from Arthrobactor sp. and rabbit antiasialo GM1 were obtained from Wako Pure Chemical Industries (Osaka, Japan). RPMI-1640 and fetal bovine serum (FBS) for culture medium was purchased from Invitrogen (Carlsbad, CA). All other reagents were obtained from commercial sources and were used without further purification.

\section{High-Pressure, High-Temperature Extract of Kumaizasa Bamboo Leaves}

Kumaizasa is a bush type of bamboo, with a wider leaf than that of the common bamboo found in southern Japan that grows predominantly in the Hokkaido region. The material used here, provided by the Cosmo Bios Research Institute (Akahira, Hokkaido, Japan), was extracted under extremely high temperature and high pressure (via two steps). First, it was extracted at $100^{\circ} \mathrm{C}$ for $60 \mathrm{~min}$, and residues were subjected to extraction at $121^{\circ} \mathrm{C}, 2 \mathrm{~atm}$, for $30 \mathrm{~min}$. Second, the residues were further treated at $196^{\circ} \mathrm{C}, 15 \mathrm{~atm}$, for $5 \mathrm{~min}$, and then extracted at $120^{\circ} \mathrm{C}$ for $30 \mathrm{~min}$. The total sugar concentration was determined by the phenol-sulfuric acid method with glucose as the standard (2). To identify the active principle in the extracts, they were subjected to a Sephadex G-50 Fine gel chromatography column (height $90 \mathrm{~cm} \times$ diameter $1.2 \mathrm{~cm}$; GE Healthcare, Uppsala, Sweden), with the elution buffer being $0.01 \mathrm{M}$ phosphatebuffered $0.15 \mathrm{M} \mathrm{NaCl}$ (PBS). Fractions were collected by monitoring absorbance at 280 and $370 \mathrm{~nm}$. The $1,3-\beta$-glucan contents of these extracts, of three major fractions of different molecular size (F-I, F-II, F-III) from the extracts and of a conventionally prepared extract were determined by using a 1,3- $\beta$-glucan assay kit consisting of limulus lysate (Maruha, Tokyo, Japan), according to the manufacturer's instructions (3). Further amount of total phenolics in the bamboo leaf extracts and major fractions were also determined according to Folin-Ciocalteu method (4). Total phenolics content was expressed as caffeic-acid equivalents.

To further characterize F-I, $10 \mathrm{mg}$ of F-I in $1 \mathrm{ml}$ of PBS, pH 7.5, was added to 200 units $\mathrm{ml}^{-1}$ of 1,3- $\beta$-glucanase, which was obtained from Arthrobactor sp., and was incubated at $25^{\circ} \mathrm{C}$ in a shaking water bath for 2 days. During the incubation, aliquots of the reaction mixture were taken at given time intervals, of which the enzyme reaction was stopped by heating at $100^{\circ} \mathrm{C}$, and then amount of free glucose generated was quantified by using a high-performance liquid chromatography (HPLC) system (LC-VP column; Shim-pack ISA-07/S2504; Shimadzu, Kyoto, Japan) with postcolumn fluorescence derivatization, which reacted with arginine.

\section{Animals}

Male ddY (8 weeks of age), C57BL/6Cr Slc mice (6 weeks of age) and female BALB/c mice were purchased from SLC, Inc. (Shizuoka, Japan). Mice were housed in groups of four or five per cage and were maintained at $22 \pm 1^{\circ} \mathrm{C}$ and $55 \pm 5 \%$ relative humidity. Lighting was automatic on a 12-h light/dark cycle. All experiments were carried out according to the Laboratory Protocol of Animal Handling, Kumamoto University.

\section{Cell Lines}

K562 cells (human chronic myeloid leukemia) and YAC1 cells (murine lymphoma) were obtained from Riken Bioresource Center Cell Bank (Tsukuba, Japan) and were maintained in RPMI-1640 containing 10\% FBS, 100 units $\mathrm{ml}^{-1}$ penicillin and $100 \mu \mathrm{g} \mathrm{ml}^{-1}$ streptomycin.

\section{Diet}

The experimental diet was prepared by Funabashi Farm (F2; Funabashi, Chiba, Japan). Bamboo leaf extracts mixed with the diet at $0.05-0.5 \%(\mathrm{w} / \mathrm{w})$ were vacuum packed followed by gamma ray sterilization and stored at $4{ }^{\circ} \mathrm{C}$ until use.

\section{Effect of Bamboo Leaf Extracts and IL-2 on In Vitro Cytotoxicity of Human Natural Killer Cells against K562 Cells}

The Conray-Ficoll method was used to isolate human peripheral blood mononuclear cells from venous blood obtained from healthy volunteers (5). Human natural killer (NK) cells from heparinized peripheral blood from healthy volunteers were collected by using a StemSep kit (StemCell Technologies, Vancouver, Canada). Bamboo leaf extracts were dissolved in PBS. NK cells $\left(2 \times 10^{6}\right.$ cells $)$ were pre-treated with either IL-2 for comparison or the extracts at final concentrations of $1-100 \mu \mathrm{g} \mathrm{ml}^{-1}$, or different fractions of the F-I, F-II, F-III and 1,3- $\beta$ glucanase-digested $\mathrm{F}-\mathrm{I}$ at $37^{\circ} \mathrm{C}$ for $48 \mathrm{~h}$ in $5 \% \mathrm{CO}_{2} /$ air. NK cells incubated with PBS were used as the control. After incubation, NK cells were washed with culture medium and then used for examination of cytotoxic activity against $2 \times 10^{4}$ target $\mathrm{K} 562$ cells in the same culture medium at various ratios [effector/target $(\mathrm{E} / \mathrm{T})$ 
ratios] ranging from $5 / 1$ to $50 / 1$ in 96 -well round-bottom microtiter plates (Becton Dickinson, Franklin Lakes, NJ). The microtiter plates were centrifuged at $200 \mathrm{~g}$ for $5 \mathrm{~min}$ to facilitate contact between effector with target cells followed by incubation at $37^{\circ} \mathrm{C}$ for $4 \mathrm{~h}$ in $5 \% \mathrm{CO}_{2} /$ air. After incubation, the viable cell number was assayed with a CellTiter-Glo Luminescent Cell Viability Assay kit (Promega, Madison, WI). NK cytotoxic activity was calculated by using the following formula: \% lysis = ( 1 - viable cells in tested group/viable cells in no-drug control group) $\times 100$, where the positive no-drug control group consisted of K562 cells treated with NK cells activated by IL-2 at $0.1-1.0 \mu \mathrm{g} \mathrm{ml}^{-1}$ in the same culture medium as the reference.

\section{In Vitro Phagocytic Activity and Nitric Oxide Production by Mouse Macrophages}

Peritoneal macrophages were obtained by intraperitoneal injection of $10 \%$ proteose peptone (Becton Dickinson) elicited in $\mathrm{BALB} / \mathrm{c}$ mice. Peritoneal macrophages $\left(1 \times 10^{5}\right.$ cells $/$ well $)$ were incubated in plastic plates $(\phi 30 \mathrm{~mm})$, with a cover glass placed in the bottom, at $37^{\circ} \mathrm{C}$ for $1 \mathrm{~h}$ in $5 \% \mathrm{CO}_{2} /$ air. Macrophages were then treated for $24 \mathrm{~h}$ with the extracts at concentrations of $0.1-100 \mu \mathrm{g} \mathrm{ml}^{-1}$, or with different fractions (F-I, F-II, F-III or 1,3- $\beta$-glucanase-digested F-I) at concentrations of $10-1000 \mu \mathrm{g} \mathrm{ml}^{-1}$. Then, $3 \mathrm{ml}$ of $1.0 \%$ suspension of yeast (Saccharomyces cerevisiae) was added, and incubation continued for $30 \mathrm{~min}$ under the same conditions. The number of yeast cells phagocytosed were counted in evaluating more than 200 macrophages under a microscope.

Macrophages were similarly obtained from C57BL $/ 6$ mice, and $1 \times 10^{5}$ cells/well) were then incubated in RPMI-1640 medium with $10 \%$ FBS at $37^{\circ} \mathrm{C}$ for $20 \mathrm{~h}$ with $1,3-\beta$-glucan from $L$. edodes at $1000 \mu \mathrm{g} \mathrm{ml}^{-1}$ as a reference, with bamboo leaf extract at $1000 \mu \mathrm{g} \mathrm{ml}^{-1}$ or with and different fractions (F-I, F-II, F-III) from the extracts at $1000 \mathrm{~g} \mathrm{ml}^{-1}$. After the incubation, the production of nitric oxide (NO) was determined by use of the Griess reagent.

\section{Activation of Mouse Macrophages by Lipopolysaccharide or Lipopolysaccharide Plus IFN- $\gamma$}

Peritoneal macrophages were obtained by intraperitoneal injection of $10 \%$ proteose peptone. These macrophages $\left(1 \times 10^{5}\right.$ cells/well $)$ were incubated with $1.0 \mu \mathrm{g} \mathrm{ml}^{-1}$ lipopolysaccharide (LPS) or $1.0 \mu \mathrm{g} \mathrm{ml}^{-1}$ LPS plus $0.2 \mu \mathrm{g} \mathrm{ml}^{-1}$ IFN- $\gamma$ at $37^{\circ} \mathrm{C}$ for $20 \mathrm{~h}$ in RPMI-1640 medium with $10 \%$ FBS. Then, production of IL-12 was determined by means of an enzyme-linked immunosorbent assay (ELISA) using mouse ELISA kits (Pierce Biotechnology).
In Vivo Anti-tumor Activity of the Bamboo Leaf Extract Against S-180, C38 and Meth-A Solid Tumor Models

S-180 tumors were maintained in ascitic form in ddY mice. S-180 cells $\left(2 \times 10^{6}\right)$ obtained from ascitic tumor were implanted subcutaneously (s.c.) in the dorsal skin of ddY mice. Mice bearing tumors $5-6 \mathrm{~mm}$ in diameter were selected for study of anti-tumor activity, 7-10 days after tumor cell injection. For each experiment, control mice were fed a chemically defined basal diet without bamboo leaf extract. Experimental groups were fed a diet supplemented with $0.05-0.5 \%$ of the extract. During the experiments, tumor volume, body weight, food intake and survival rate of mice were measured daily. Tumor volume (V) was calculated by use of the following formula: $\mathrm{V}=\left(\mathrm{L} \times \mathrm{W}^{2}\right) / 2$, where $\mathrm{L}$ is the longitudinal cross-section and $\mathrm{W}$ is the transverse section of the solid tumor. Eight mice were used for each group. Similar experiments were carried out with the C38 solid tumor model, in which tumor fragments of about $30 \mathrm{mg}$ were implanted s.c. in the dorsal skin of $\mathrm{C} 57 \mathrm{BL} / 6$ mice by using a trocker needle.

In addition, anti-tumor activity of bamboo leaf extract was examined in the Meth-A solid tumor model. As with S-180 tumors and Meth-A cells were maintained by intraperitoneal passage in $\mathrm{BALB} / \mathrm{c}$ mice. Meth-A cells $\left(1 \times 10^{6}\right)$ were implanted s.c. in the dorsal skin of BALB/c mice, and 7 days later when the tumor diameter was $\sim 5 \mathrm{~mm}$, the anti-tumor experiment was conducted via the same protocol as that described above.

\section{Effect of Bamboo Leaf Extracts on Cytokine Induction and NK Cell Activation in C38 Tumor-bearing Mice}

As in the aforementioned protocol, C38 tumors were implanted in C57BL/6 mice, and when tumors became palpable ( $\phi$ approx $4 \mathrm{~mm}$ ), mice were fed a diet containing bamboo leaf extract. At 21 days after treatment, all mice were killed under ether anesthesia, and blood, spleen and tumor samples were obtained, for quantification of serum IL-2, IL-12 and IFN- $\gamma$ by using mouse ELISA kits (Pierce Biotechnology). Splenic NK cells were prepared by using a StemSep kit, and cytotoxicity of NK cells against target YAC-1 cells cultured in vitro in RPMI1640 medium with $10 \%$ FBS was examined. Each tumor sample was also weighed.

To investigate the role of NK cells in anti-tumor activity induced by the extracts, a similar set of in vivo experiments was carried out by eliminating NK cell function with anti-asialo GM1 antibody in C38 solid tumor. When C38 tumors were $\sim 4 \mathrm{~mm}$ in diameter, one group of mice was fed a diet containing bamboo leaf extract at $0.1 \%$, and then mice were injected intravenously with diluted (4 times) anti-asialo GM1 antibody on days 12, 15 and 19 (6). Another group fed with the same diet did not receive the antibody treatment. 


\section{Statistical Analyses}

All data were expressed as means $\pm \mathrm{SD}$. Student's $t$-test was used to determine the significance of differences between each experimental group.

\section{Results}

\section{Comparison of Efficiency of Vigorous High-temperature, High-pressure Extraction and Hot-water Extraction}

To compare the efficiency of our high-temperature, highpressure multi-step extraction method and the conventional hot-water (boiling water) extraction method, for each soluble extract we quantified the amount of total sugar (glucose equivalent), optical absorption and phenolic compound at every step. Figure 1 shows that the total sugar content of extracts obtained via the vigorous extraction method was about five times higher than that obtained via hot-water extraction. Moreover, UV absorption of the extracts was also about six times higher both

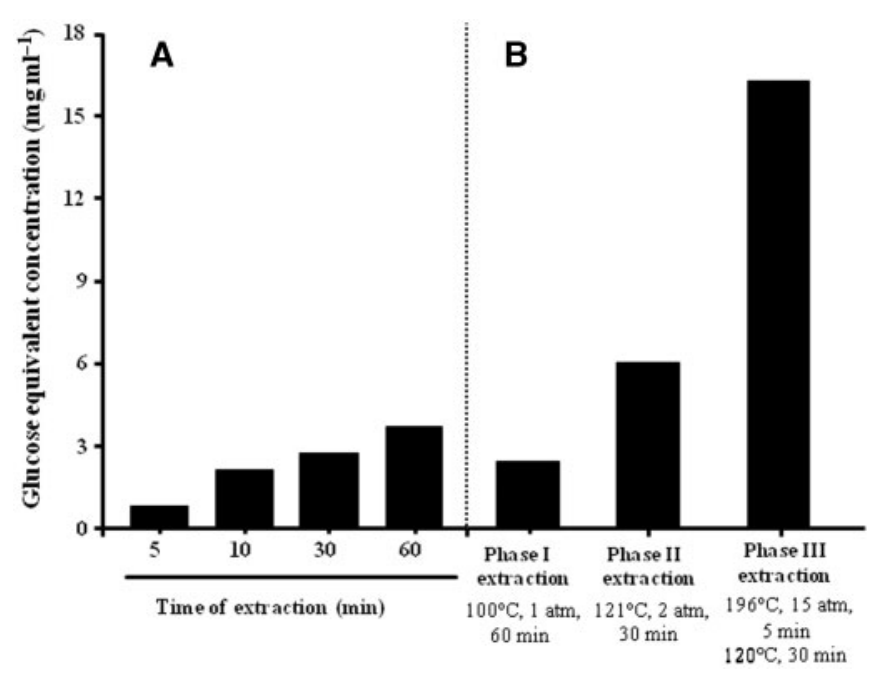

Figure 1. Comparison of the efficiency under conventional hot-water extraction (A) and under multi-step vigorous high-temperature, highpressure extraction (B). Extraction of each step is shown in B. at 280 and $370 \mathrm{~nm}$ compared to that of hot-water extraction (Table 1). Further, total phenolics content from the vigorous extraction was two times higher than that from hot-water extraction (Table 1).

To identify the active principle(s) in the extracts, we used Sephadex G-50 gel chromatography for purification. The extracts contained three major fractions: F-I $(>5 \mathrm{kDa}$ but $<20 \mathrm{kDa})$; F-II $(1-2 \mathrm{kDa})$ and F-III $(<1 \mathrm{kDa})$ (Fig. 2A). F-I contained 1,3- $\beta$-glucan, as revealed by the modified limulus test, which is specific for 1,3- $\beta$-glucan (Table 1). About $65 \%(\mathrm{w} / \mathrm{w})$ free glucose was recovered from F-I by 1,3- $\beta$-glucanase digestion (Fig. 2C), which indicates that the majority of F-I was $1,3-\beta$-glucan; the remaining portion requires further chemical classification. In comparison, the elution profile of preparation by the conventional extraction method was completely different from that of vigorous extraction (Fig. 2A versus 2B).

\section{Effect of Bamboo Leaf Extracts on In Vitro Cytotoxic Activity of Human NK Cells}

To examine biological activities of unfractionated bamboo leaf extracts, we first evaluated their cytotoxic activity of NK cells in vitro. Cytotoxic NK activity against K562 cells increased in parallel with the increase in the $\mathrm{E} / \mathrm{T}$ ratio (Fig. 3), with the $100 \mu \mathrm{g} \mathrm{ml}^{-1}$ extract at the $\mathrm{E} / \mathrm{T}$ of 50 showing the highest cytotoxicity. More important, the extracts showed that its immunopotentiating effect on NK cell cytotoxicity was comparable to that of pure IL-2 (Fig. 3A versus 3B). This NK cell activation of F-I was suppressed about $50 \%$ by 1,3 - $\beta$-glucanase digestion, which indicates a role for $1,3-\beta$-glucan (Fig. 3C).

\section{The Effect of Bamboo Leaf Extracts on Phagocytic Activity and Production of NO by Mouse Macrophages}

The extracts significantly increased macrophage phagocytic activity compared with the untreated group (Fig. 4A), with phagocytic activity induced by the extracts being

Table 1. Incresed extract ability: comparisons between conventional versus vigorous extraction, and each values of the Sephadex G50

\begin{tabular}{|c|c|c|c|c|}
\hline \multirow[t]{2}{*}{ Sample } & \multirow{2}{*}{$\begin{array}{l}\text { Amount of } \\
1,3-\beta \text {-glucan } \\
\left(\mu \mathrm{g} \mathrm{mg}^{-1}\right)^{\mathrm{a}}\end{array}$} & \multirow{2}{*}{$\begin{array}{l}\text { Amount of } \\
\text { total phenolics } \\
\left(\mu \mathrm{g} \mathrm{m}^{-1}\right)^{\mathrm{b}}\end{array}$} & \multicolumn{2}{|c|}{$\begin{array}{l}\text { Value of absorbance, relative } \\
\text { (fold increase) }\end{array}$} \\
\hline & & & $280 \mathrm{~nm}$ & $370 \mathrm{~nm}$ \\
\hline Extract from vigorous extraction (unpurified) & 316.5 & 65.2 & $202.0(\times 5.7)$ & $43.5(\times 6.1)$ \\
\hline \multicolumn{5}{|l|}{ Sephadex G-50 fractions } \\
\hline F-I & 317.3 & 6.3 & 0.3 & 0.1 \\
\hline F-III & 0.001 & 17.1 & 0.9 & 0.4 \\
\hline
\end{tabular}

${ }^{a}$ Determined by using the modified Limulus test, which is specific for $\beta$-glucan (3). See total sugar content by phenol-sulfuric a acid method in Figure 1; ${ }^{\mathrm{b}}$ Determined using Folin-Ciocalteu method (4). 

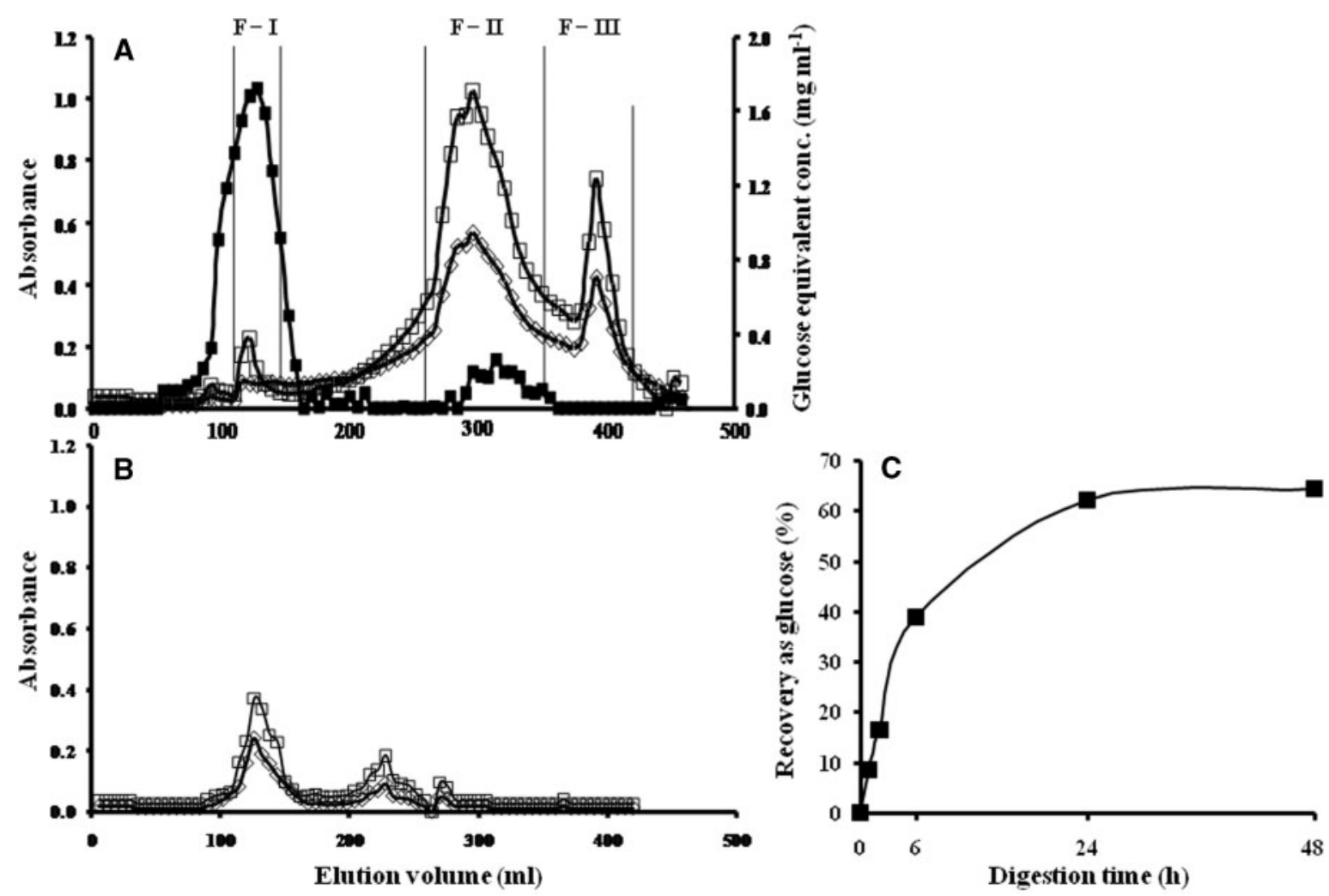

Figure 2. (A) Sephadex G-50 gel chromatography of bamboo leaf extracts under vigorous condition and conventional condition (B). Absorbance at $280 \mathrm{~nm}$ (open square); absorbance at $370 \mathrm{~nm}$ (open diamond). Values of glucose equivalent obtained by the phenol-sulfuric acid method (closed square). Each tube contained $6.0 \mathrm{ml}$. (C) Time course of liberation of free glucose during digestion of $10 \mathrm{mg} \mathrm{ml}{ }^{-1} \mathrm{~F}-\mathrm{I}$ with $200 \mathrm{units}$ of 1,3 - $\beta$-glucanase (see text for details).

about two to three times higher at $1.0,10$ and $100 \mu \mathrm{g} \mathrm{ml}^{-1}$ than that of the control. Figure 4B illustrates phagocytic activity of macrophage induced by each fraction: F-I (1,3- $\beta$-glucan) significantly increased. This result was similarly seen in the unfractionated extract. However, this potentiation of phagocytotic activity of F-II was not so apparent, and also the 1,3- $\beta$-glucanase-digested F-I fraction had almost no activity (F-I versus digested F-I at 100 or $1000 \mu \mathrm{g} \mathrm{ml}^{-1}$ ). F-III seemed to have $<10 \%$ of the activity of F-I. Figure 4C shows that bamboo leaf extract and F-I significantly increased macrophage NO production, similar to $1,3-\beta$-glucan from $L$. edodes. F-I induced higher NO production than the original unfractionated extract, whereas F-II and F-III caused almost no increased NO production.

Effect of Mouse Strain, C57BL/6 versus BALB/c, on Activation of Macrophages by LPS or LPS Plus IFN- $\gamma$

As shown in Fig. 5, macrophages from both mouse strains stimulated by LPS or LPS plus IFN- $\gamma$ showed significantly increased IL-12 and NO induction compared with untreated groups. A notable finding was that C57BL/6 macrophages produced 10 times higher amounts of IL-12 and NO than BALB/c macrophages.

\section{Anti-tumor Activity of Bamboo Leaf Extracts in Mice}

\section{S-180 Solid Tumor in the ddY Mouse Model}

All doses of bamboo leaf extracts significantly suppressed tumor growth compared with the control, with the extracts at the $0.1 \%$ concentration showing the strongest activity (Fig. 6A). This treatment also greatly improved the survival rate of tumor-bearing mice, again with the extracts at $0.1 \%$ producing the highest survival: i.e. the $\% \mathrm{~T} / \mathrm{C}$ (treated/control) was $142.6 \%$ (Fig. 6B). Furthermore, a significant number of tumors in mice fed with bamboo leaf extracts regressed completely; the numbers of tumor-free mice after treatment/initial numbers of tumor-bearing mice were $1 / 8,3 / 8$ and $2 / 8$ at extract concentrations of $0.05,0.1$ and $0.5 \%$, respectively. Treated groups showed no significant difference in body weight (data not shown).

To compare anti-tumor activity of the conventional boiling water $\left(100^{\circ} \mathrm{C}\right)$ extraction and the vigorous extraction methods, a similar set of in vivo experiments was performed in S-180 solid tumor model with the extracts at the $0.1 \%$ concentration. Tumor growth was not suppressed in the conventional extraction group (Fig. 6C). 

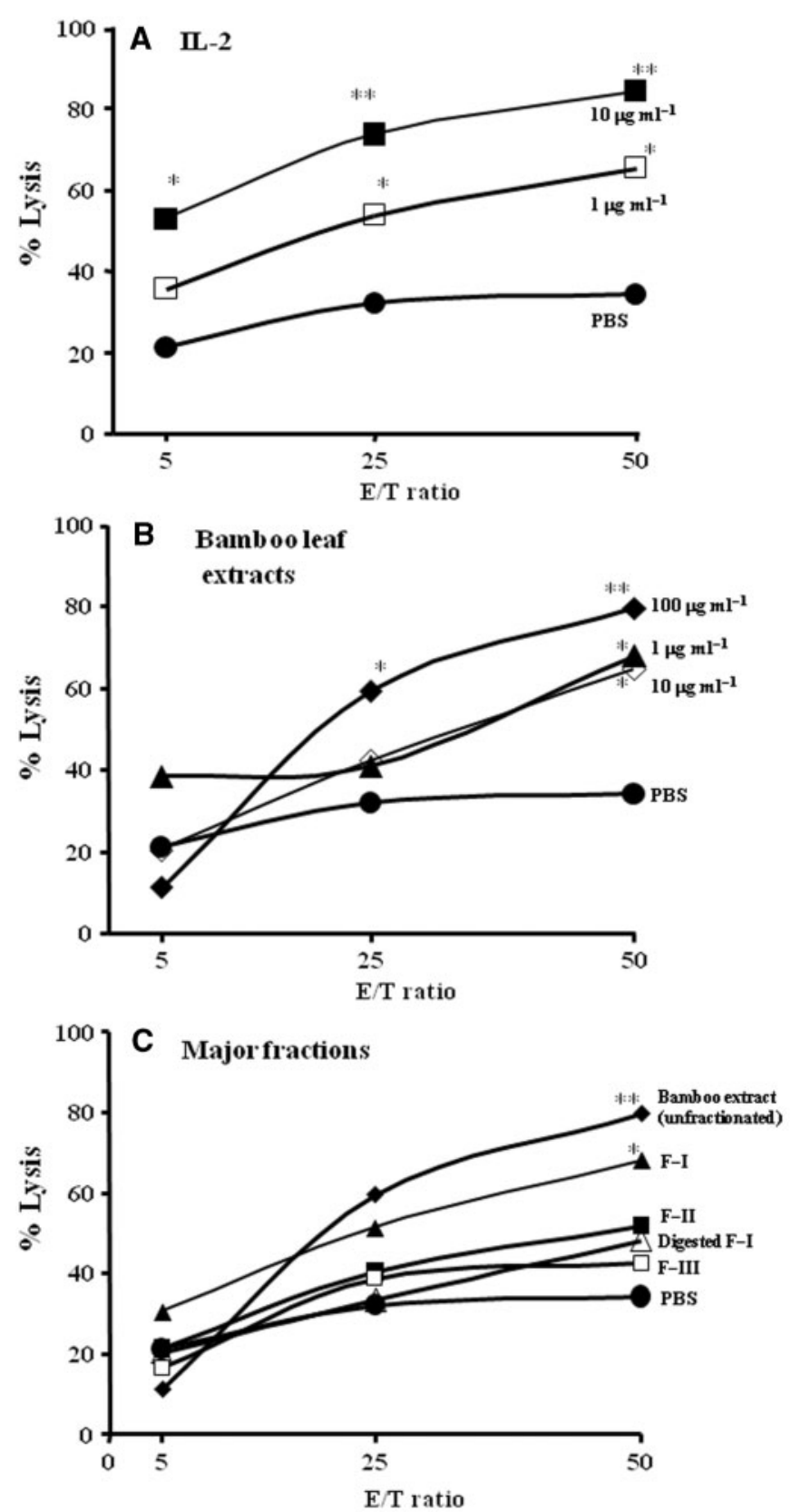

Figure 3. Enhancement of cytotoxic activity of human NK cells at various concentrations of bamboo leaf extract at different $\mathrm{E} / \mathrm{T}$ ratios ( $n=8$ /group). Suspensions of effector NK cells were added to target K562 cells at E/T ratios of 5:1, 25:1 or 50:1. (A) Cytotoxic activity for control, PBS (closed circle); IL-2 at $1 \mu \mathrm{g} \mathrm{ml}^{-1}$ (open square); IL-2 at $10 \mu \mathrm{g} \mathrm{ml}^{-1}$ (closed square). (B) That for bamboo leaf extracts at $1 \mu \mathrm{g} \mathrm{ml}^{-1}$ (closed triangle), $10 \mu \mathrm{g} \mathrm{ml}^{-1}$ (open diamond) and $100 \mu \mathrm{g} \mathrm{ml}^{-1}$ (closed diamond). (C) That for unfractionated bamboo leaf extract at $100 \mu \mathrm{g} \mathrm{ml}^{-1}$ (closed diamond), F-I at $100 \mu \mathrm{g} \mathrm{ml}^{-1}$ (closed triangle), F-II at $100 \mu \mathrm{g} \mathrm{ml}^{-1}$ (closed square), F-III at $100 \mu \mathrm{g} \mathrm{ml}^{-1}$ (open square), $1,3-\beta$ glucanase-digested F-I at $100 \mu \mathrm{g} \mathrm{ml}^{-1}$ (open triangle) and PBS (closed circle). Values represent means $\pm \mathrm{SD}$. ${ }^{* *} P<0.01$ and $* P<0.05$ versus controls.

\section{C38 Solid Tumor in the C57BL/6 Mouse Model}

As Fig. 7A shows, bamboo leaf extract significantly suppressed tumor growth compared with the control. This treatment also greatly improved the mean survival rate $(\% \mathrm{~T} / \mathrm{C}$ was $158 \%)$ (Fig. $7 \mathrm{~B})$.

\section{Change in Immunological Parameters in C38 Tumor-bearing Mice}

Bamboo leaf extract at $0.1 \%$ also significantly suppressed C38 tumor growth at 21 days after treatment compared with the control (Fig. 8). The average tumor weight of the treated group was $1.54 \pm 0.46 \mathrm{~g}$, whereas that of the untreated control group was $2.65 \pm 0.51 \mathrm{~g}$, significantly higher.

To further clarify the anti-tumor effect of the bamboo leaf extracts, we measured IL-2, IL-12 and IFN- $\gamma$ levels in mice after feeding the extract in the diet for 21 days. Serum levels IL-12 and IFN- $\gamma$ were significantly raised in $\mathrm{C} 38$ tumor-bearing mice fed with extracts at the $0.1 \%$ concentration compared with levels in the control group (Table 2). More important, a significantly higher $(P<0.01)$ concentration of IL-12 was induced by the extracts, which may stimulate NK cell activity, and, in fact, significantly elevated cytotoxic activity of splenic NK cells occurred in C38 tumor-bearing mice (Fig. 8B).

To clarify anti-tumor activity mediated by the NK cells, we used anti-asialo GM1 antibody in the C38 tumor model. Mice fed the bamboo leaf extract at $0.1 \%$ had significantly suppressed tumor growth, whereas a similar group of mice that received the extracts and anti-asialo GM1 antibody treatment showed no significant suppression of tumor growth, with tumor volume being similar to that of the control (Fig. 9).

\section{Meth-A Solid Tumor in the BALB/c Mouse Model}

The bamboo leaf extract had no significant effect on Meth-A tumor growth and survival rate of mice compared with the control (data not shown). This finding is consistent with the fact that this strain had a much lower response than that of the C57BL/6 strain (about $10 \%$ ) to LPS or LPS plus IFN- $\gamma$ treatment, as shown in Fig. 5.

\section{Discussion}

Alternative therapeutic tools obtained from plants to fight cancer have garnered great interest. In the present study, we demonstrated the remarkable anti-tumor activity of bamboo leaf extracts obtained under vigorous high-temperature, high-pressure extraction conditions. To our surprise, these extracts had far superior activity than extracts obtained via the conventional hot water method, as seen in Table 1, Fig. 1 and Fig. 6C. This new aqueous extraction method not only yielded a higher 


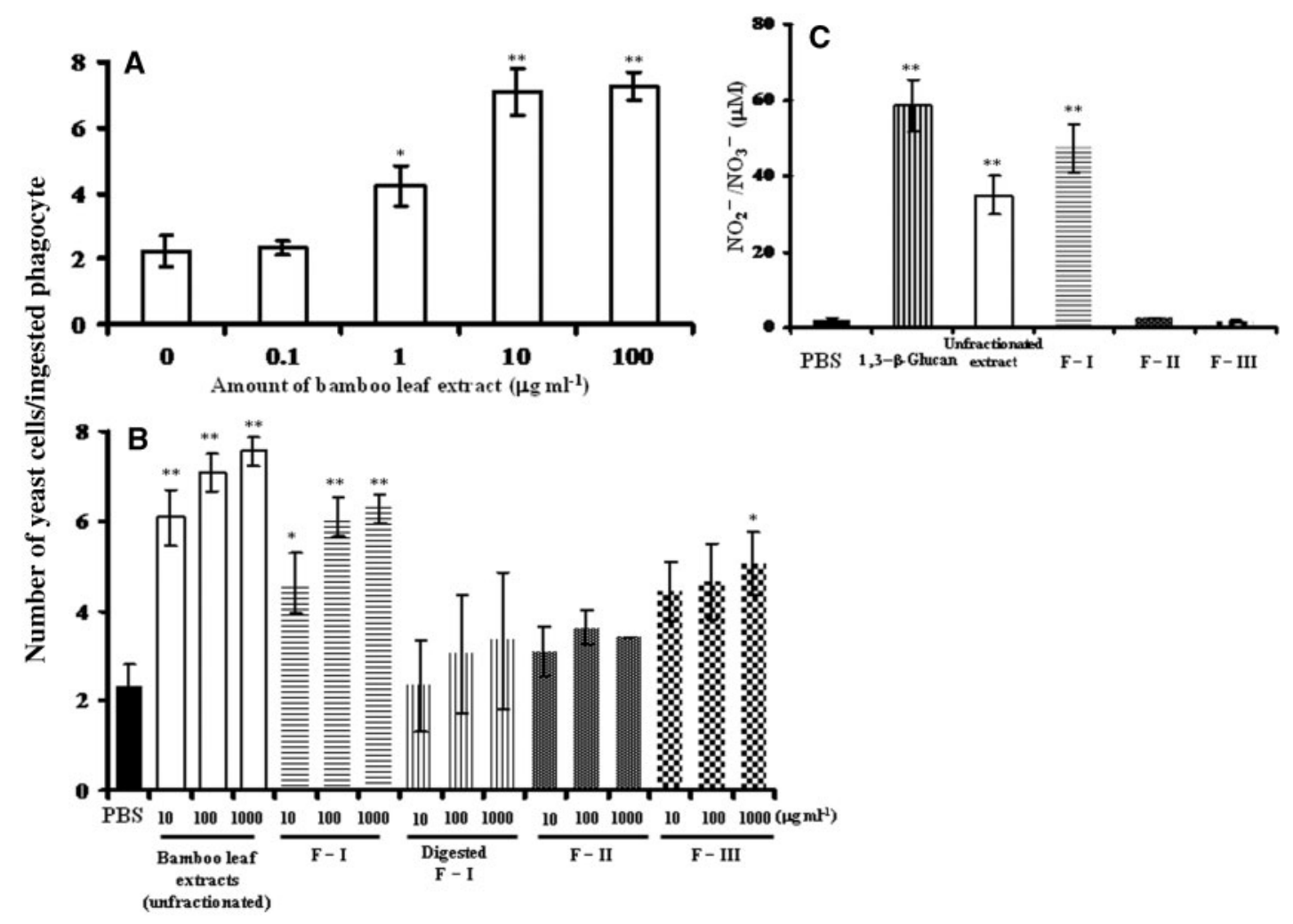

Figure 4. In vitro phagocytic activity of peritoneal macrophages from the ddY mouse (A and B), and NO production by C57BL/6 mouse macrophages $(\mathbf{C})$. ddY mouse macrophages were treated with different doses of bamboo leaf extracts; control macrophages did not receive the extracts (A). (B) Macrophages were treated with different doses of unfractionated bamboo leaf extracts or different fractions (F-I, F-II, F-III and 1,3- $\beta$-glucanase-digested F-I) of extract, or PBS (control). (C) Macrophage NO production after treatment with PBS (control), 1,3- $\beta$-glucan from L. edodes (reference), unfractionated bamboo leaf extract, F-I, F-II or F-III at $100 \mu \mathrm{g} \mathrm{ml}^{-1}$. Values represent means $\pm \mathrm{SD}(n=3)$. $* * P<0.01$ and ${ }^{*} P<0.05$ (extracts versus control).

amount of extract from the leaves but also greatly increased the immunopotentiation effect of the extracts (Fig. 6C). Preliminary extract purification with Sephadex G-50 and G-100 chromatography produced three major fractions of different molecular size: F-I was large, between 5 and $20 \mathrm{kDa}$; F-II was of medium size, $1-2 \mathrm{kDa}$; and F-III was small, $<1 \mathrm{kDa}$ (Fig. 2A). F-II and F-III were not obtained by the conventional hot water extract (Table 1). F-I contained predominantly 1,3 - $\beta$-glucan because $1,3-\beta$-glucanase digested the majority of F-I free glucose (Fig. 2C).

With regard to biological activity, F-I significantly augmented the phagocytic activity of macrophages (Fig. 4B) to a degree similar to that achieved by unfractionated bamboo leaf extract (Fig. 4A). F-I digestion by 1,3- $\beta$-glucanase eliminated the enhancing potency of the phagocytic activity of F-I (Fig. 4B). F-II showed almost no activity and F-III, only very weak activity. Furthermore, F-I, similar to unfractionated bamboo leaf extract, significantly increased macrophage NO production (Fig. 4C). This F-I-stimulated NO production was comparable in potency to that of 1,3- $\beta$-glucan from $L$. edodes, an immunopotentiating agent approved for use in Japan. F-II and F-III did not increase NO production compared with controls.

As shown in Table 1 and other data in Results section, the present preparation (vigorous extraction) and conventional hot-water extraction product were greatly different in the quality and quantity, namely the chromatographic pattern upon Sephadex G-50 column, UV absorbing components as well as phenolic contents (Figs. 1A, B and 2A, B). The difference in biological activity was immense: practically no anti-tumor activity in the conventional extracts was seen, while the present extracts were clearly effective even at $0.05 \%$, and more so at $0.1 \%$ in the diet (Fig. 6C). This again shows qualitative difference between the two extractions.

Cytotoxic activity of human NK cells obtained from peripheral venous blood of healthy volunteers was increased by bamboo leaf extracts at $\mathrm{E} / \mathrm{T}$ ratios of 5, 25 and 50 (Fig. 3). Among the three major fractions, F-I induced the greatest increase in cytotoxic activity of these NK cells (Fig. 3C). Digestion of F-I by 1,3- $\beta$-glucanase resulted in little cytotoxic activity (Fig. 3C). Significant NK cell activation by the extract was also observed in tumor-bearing C57BL/6 mice (Fig. 8B). Depletion of NK 

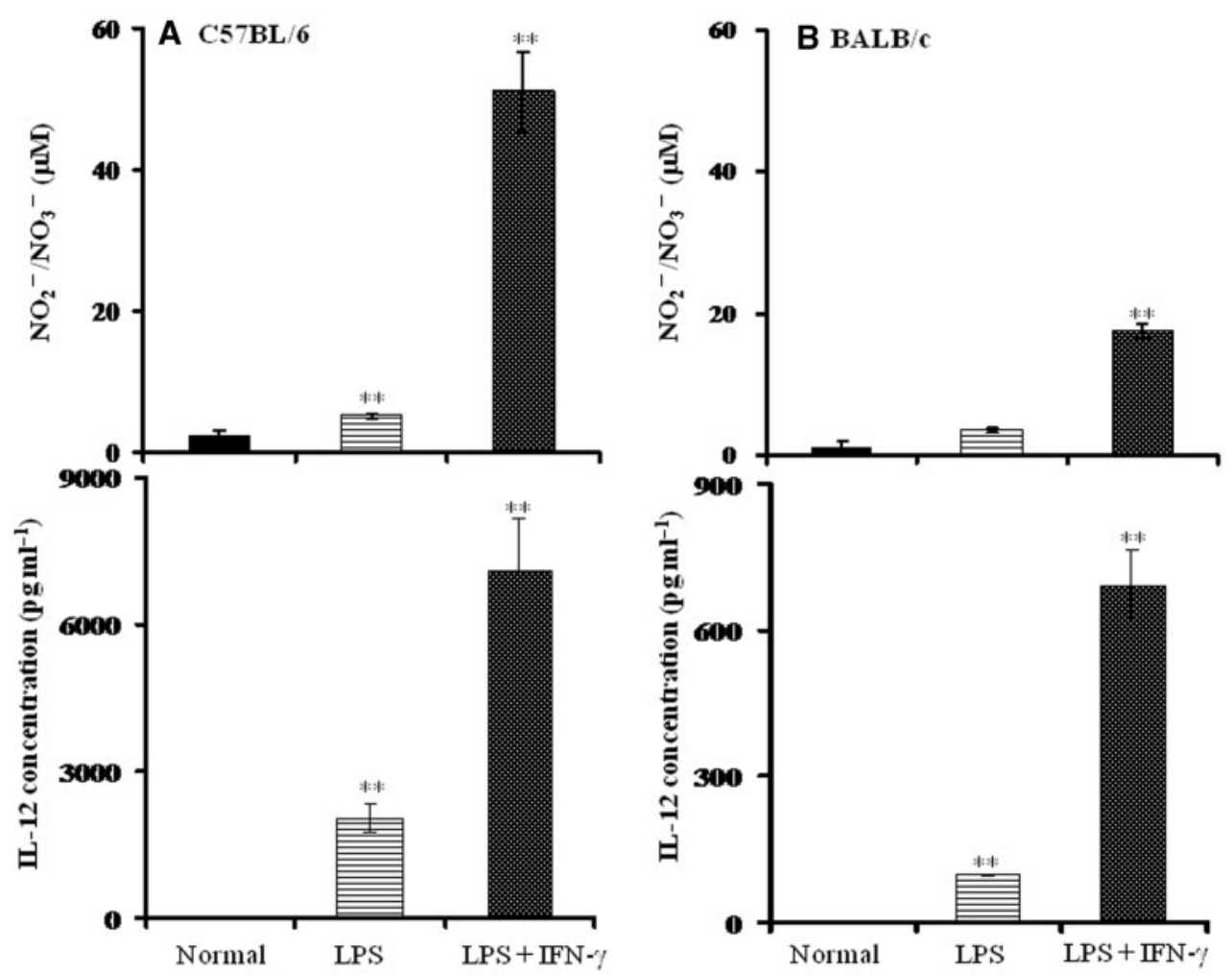

Figure 5. Difference in LPS response among different mouse strain-C57BL/6 (A) and BALB/c (B) - as related to macrophage response (IL-12 and NO induction) to activation by LPS or LPS plus IFN $-\gamma$. Macrophages were obtained as described in Methods. Note the great difference in the scale of the ordinates. Values are means \pm SD. ${ }^{*} P<0.05$ and $* * P<0.01$ versus the normal group.

cells with anti-asialo GM1 antibody in the C38 tumor model eliminated this anti-tumor activity (Fig. 9). Thus, NK cells appeared to serve as a major effector of tumor growth suppression (Figs 6A, 7A and 9).

Marked anti-tumor activity as evidenced by an improved survival was found for extracts in S-180 and C38 tumor-bearing mice (Figs 6B and 7B). However, improved survival was not the case for Meth-A tumorbearing $\mathrm{BALB} / \mathrm{c}$ mice. It is interesting to note that BALB/c mice are known to have a low response to LPS and IL-12. C57BL/6 macrophages produced 10 times more IL-12 and NO than did BALB/c macrophages (Fig. 5). This finding may indicate that a low immune response to bamboo leaf extract in $\mathrm{BALB} / \mathrm{c}$ mice may result in the poor -tumor response against Meth-A tumor in this mouse strain.

We demonstrated that serum levels IL-12 and IFN- $\gamma$ and splenic NK cell activity were significantly raised in C38 tumor-bearing mice fed with extract at the $0.1 \%$ concentration compared with levels in the control group (Table 2, Fig. 8). These results suggest that the extracts magnified the immune response even in the host bearing tumor, thereby suppressing tumor growth.

In any case, the potency of these anti-tumor activities is comparable or similar to, published results with an advanced formulation technology (liposome formulation) of conventional anti-cancer agents, such as cisplatin
(CDDP) or Adriamycin ${ }^{\circledR}$ (ADM) in the same mouse models (7). The tumor inhibition rates for these ADM and CDDP were 55.3 and $72.6 \%$ in S-180 solid tumor model $(8,9)$. In our study, bamboo leaf extracts at the concentration of $0.1 \%$ showed $70.1 \%$, which is comparable to that of $\mathrm{ADM}$ and CDDP. Thus, these results indicate that the high-temperature and high-pressure extracts of bamboo leaves can offer a potential and alternative for anti-tumor strategy without any obvious toxicity.

We reported earlier that a hot-water extract of shitake mushroom, KS-2, which contained water-soluble mannan and glucans, could be absorbed after oral administration, enter the blood circulation and accumulate in the kidney, liver and lymph nodes via intestinal uptake (10-12). Furthermore, some polysaccharide fragments were recovered from urine. This intestinal uptake and entry into circulation may also be valid for these bamboo leaf extracts, because of a similar chemical entity, $\beta$-glucan (12).

Several polysaccharide preparations such as lentinan, schizophyllan, krestin and KS-2 contain $\beta$-glucans (or 1,3 - $\beta$-glucans) and that from various species of other mushrooms (Agaricus blazei) (10-19). Among these preparations, lentinan and krestin were approved by Japanese Government and are used as biological response modifiers for anti-cancer. Their immunostimulating effect 


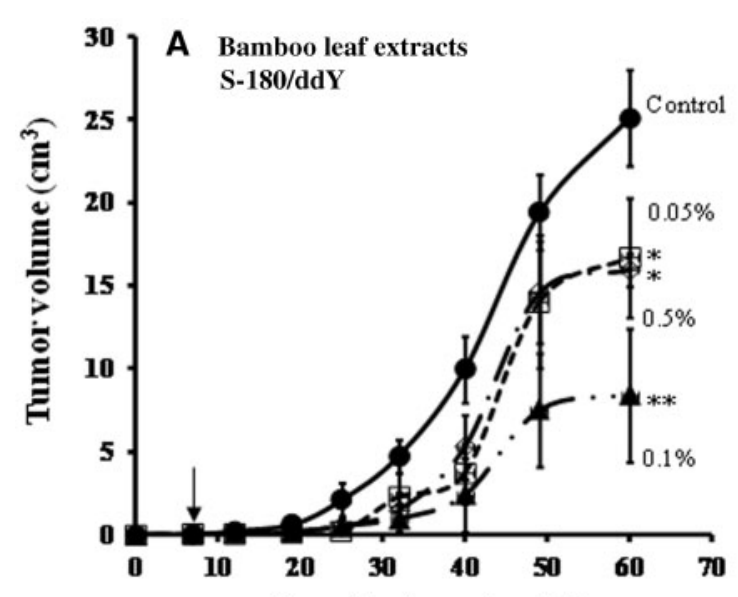

Days after tumor inoculation

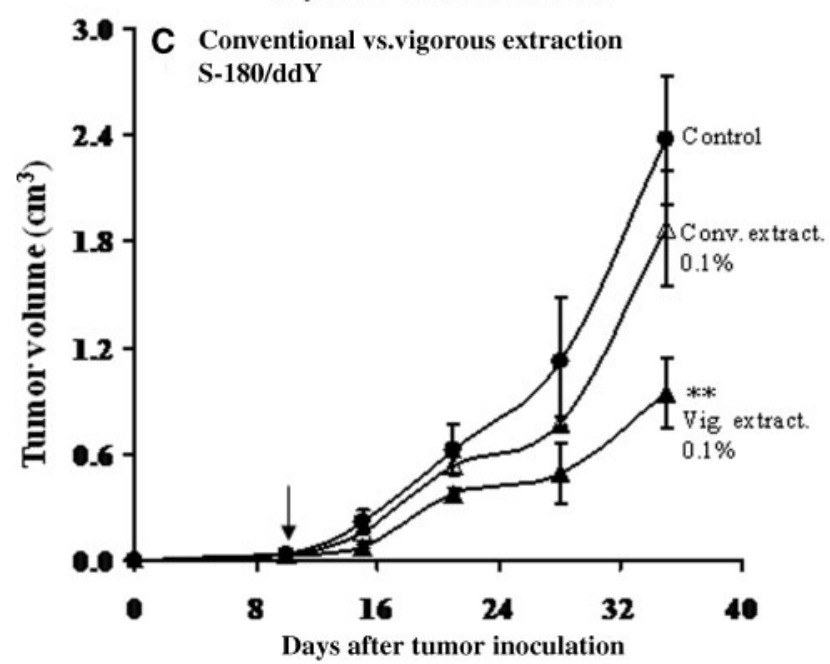

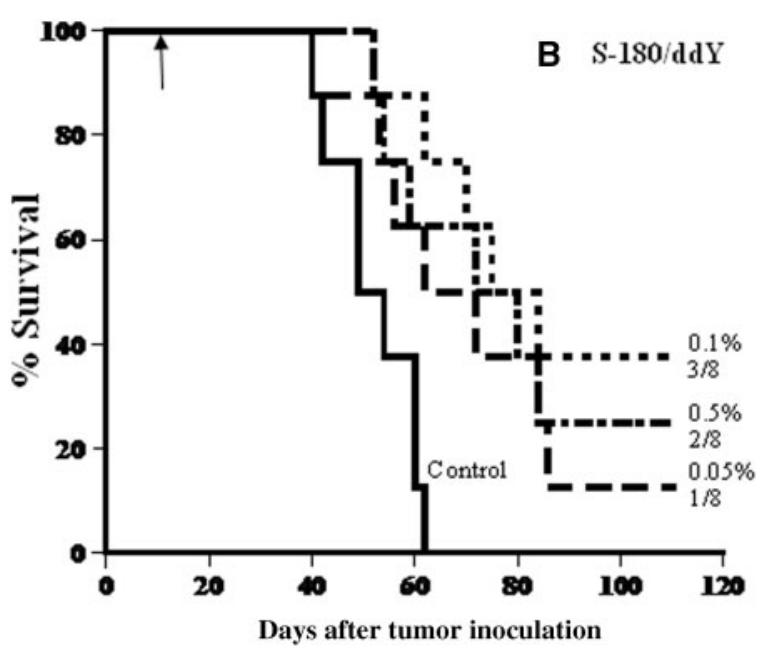

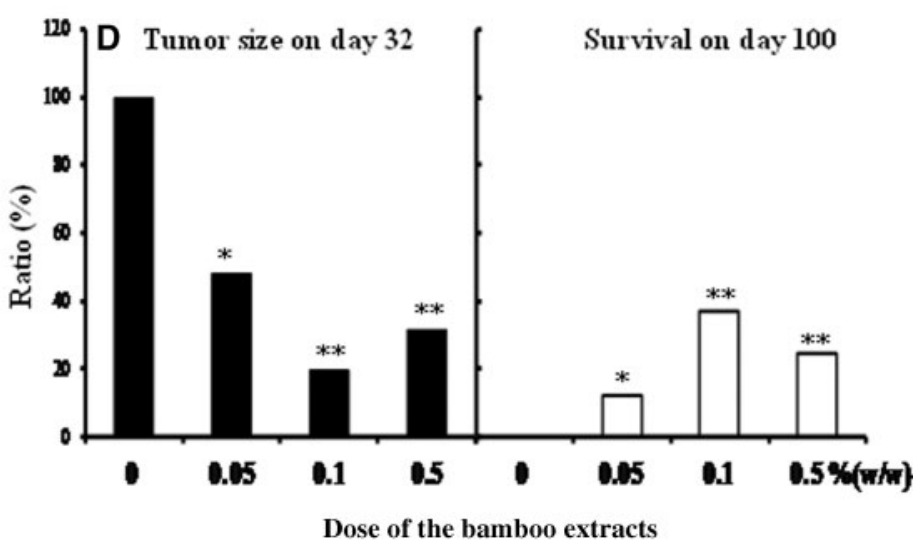

Figure 6. Anti-tumor activity of bamboo leaf extracts. Tumor growth (A), and survival curves (B), for S-180-bearing ddY mice fed with the whole extract. (C) A comparison of anti-tumor activity between vigorous extraction and conventional hot-water extraction in S-180-bearing ddY mice. ddY mice were inoculated with $2 \times 10^{6} \mathrm{~S}-180$ cells. (A) Anti-tumor activity of the control die and of the diets containing bamboo leaf extracts added at $0.05 \%$ (open square), $0.1 \%$ (closed triangle) or $0.5 \%$ (open diamond). Values are means \pm SD. $* P<0.05$ and $* * P<0.01$ versus controls. The arrow indicates the starting point of feeding the diet containing the extracts. (B) Survival curves for the control diet and the diets containing bamboo leaf extracts at $0.05,0.1$ or $0.5 \%$. Numbers of tumor free mice after treatment were (tumor free/tumor). (C) Anti-tumor activity of the control diet (closed circle) and of diets containing bamboo leaf extract (at $0.1 \%$ ) produced via the conventional hot-water method (open triangle) or the vigorous extraction method (closed triangle). ${ }^{* *} P<0.01$ versus the control. (D) Dose response on tumor size on day 32 (left) and survival on day 100 (right).
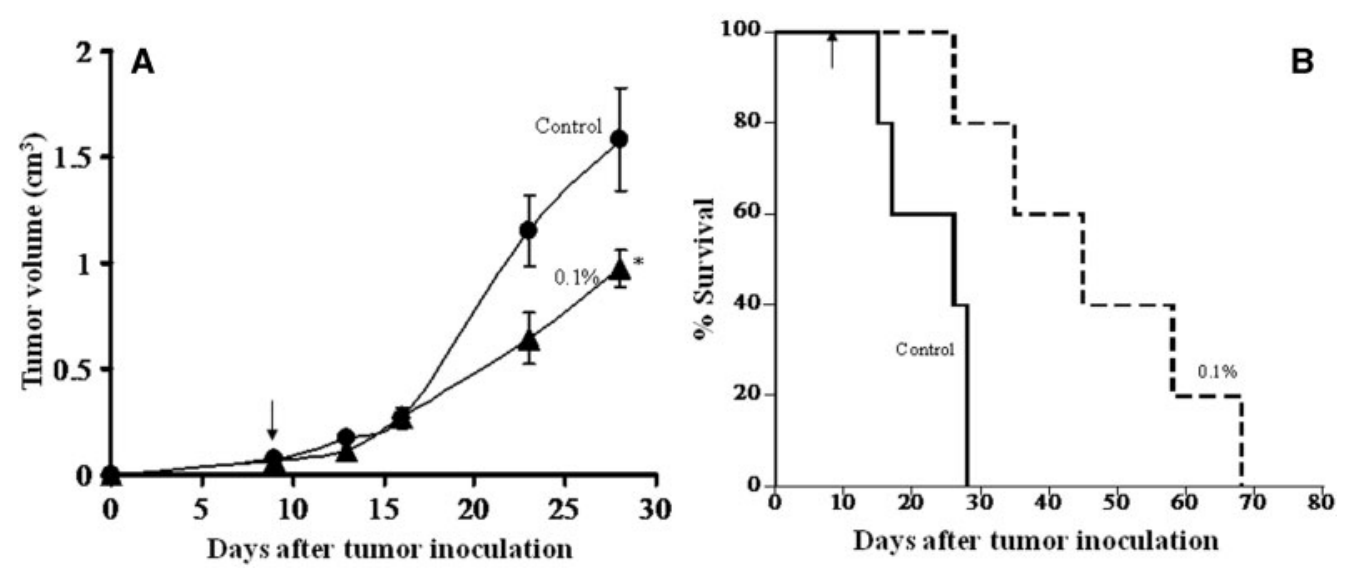

Figure 7. Anti-tumor activity of bamboo leaf extract (A) and survival curves (B) in the C38 solid tumor model. Mouse colon C38 tissue specimens (about $30 \mathrm{mg}$ ) were implanted s.c. in C57BL/6 mice. (A) Anti-tumor activity of the control diet (closed circle) and of the diet containing bamboo leaf vigorous extract at $0.1 \%$ (closed triangle). $* P<0.05$ versus the control. (B) Survival curves for the control diet and the diet containing bamboo leaf extract added at $0.1 \%$. 

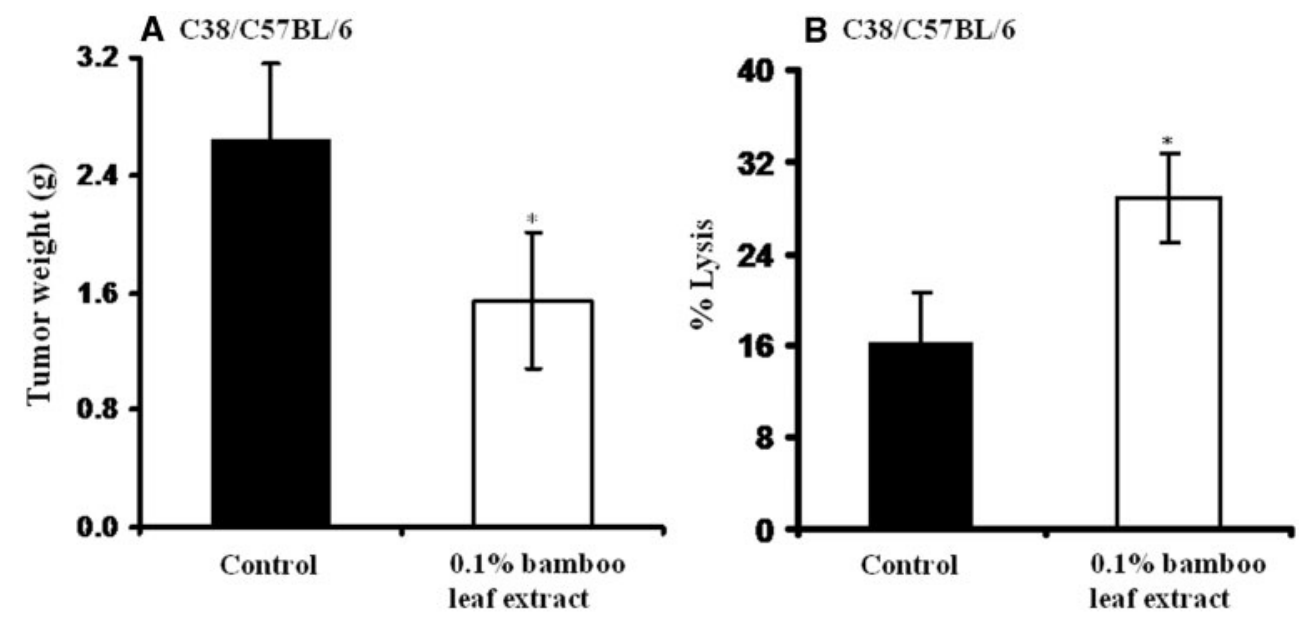

Figure 8. Anti-tumor activity of bamboo leaf vigorous extracts. (A) Weight of C-38 solid tumors after feeding of bamboo leaf extract at $0.1 \%$ in the diet for 21 days ( $n=8$ /group). (B) splenic NK cell cytotoxic activity in the C38 solid tumor-bearing mice. Values are means \pm SD. ${ }^{*} P<0.05$ versus the control. Effector NK cell suspension was added to target Yac-1 cells at the ratio of 50:1. Values are means $\pm \mathrm{SD}$. $* P<0.05$ versus the control.

Table 2. Effect of bamboo leaf extracts on serum cytokine in C38 tumor-bearing $\mathrm{C} 57 \mathrm{BL} / 6$ mice

\begin{tabular}{llll}
\hline Sample & \multicolumn{3}{c}{ Cytokine content $\left(\mathrm{pg} \mathrm{ml}^{-1}\right)$} \\
\cline { 2 - 4 } & IL-2 & IL-12 & IFN- $\gamma$ \\
\hline Control (no extract) & $25.7 \pm 2.3$ & $1266.3 \pm 256.3$ & $69.5 \pm 7.9$ \\
Bambool leaf extracts & $35.8 \pm 2.1$ & $2223.1 \pm 544.0^{*}$ & $119.8 \pm 24.8^{*}$ \\
\hline
\end{tabular}

$n=8 /$ group.

$* P<0.05$.

Bamboo leaf extracts: extracts were fed at a concentration of $0.1 \%$ in the diet for 21 days. Blood was obtained for analaysis on day 21 after tumor injection. IL, interleukin; IFN, interferon.

results in activation of not only NK cells but also macrophages, which are known to produce IL-12 and induce production of IFNs, and thus anti-tumor effects as well (18). We (KS-2) and others (A. blazei and other mushrooms) discussed that these anti-tumor activity was mediated by multiple elements such as induction of IFN- $\gamma$, IL-2 and IL-12 and activation of macrophages and NK cells (10-18).

A dietary supplementation of vegetable soup preparation given in clinical trials with patients having stage III and IV non-small cell lung cancer was reported $(20,21)$. The diets, which contain vegetables and fruits with multiple functional components have no side-effects, and believed to be effective for prevention of cancer and inflammation. On the basis of data presented here, we believe that an extract from leaves of Kumaizasa has a beneficial role in cancer treatment, via stimulating the immune response, and cancer prevention. Another candidate macromolecular components in plants, lignin is also known to have very potent radical-scavenging activity $(22,23)$, thus it may also warrant attention.

Treatment of tumors with conventional cytotoxic agents can reduce the number of cells to not less than $10^{7}-10^{10}$, but often simultaneously with suppression of

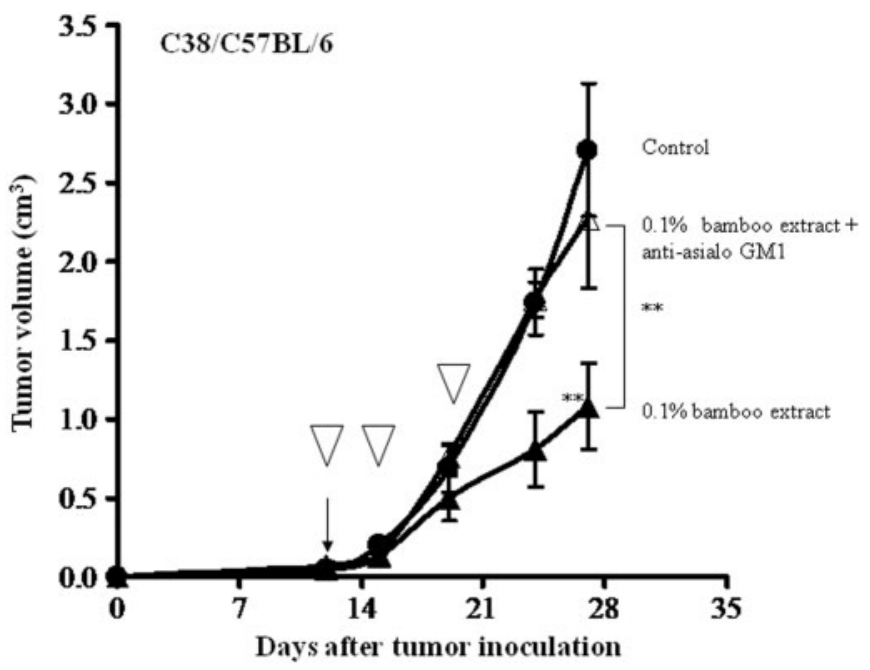

Figure 9. Involvement of NK cells anti-tumor activity of bamboo leaf extract in the C38 solid tumor model. Anti-tumor activity of the control diet (closed circle), the diet containing the extract at $0.1 \%$ (closed triangle), or the diet containing the extract at $0.1 \%$ plus treatment with anti-asialo GM1 antibody (open triangle). The open inverse triangle indicates injection of anti-asialo GM1 antibody. ${ }^{* *} P<0.01$ versus the control. The arrow at day 12 indicates the start of dietary extract feeding of the test group.

the host's immune system. On the contrary, injection of tumor cells of about $5 \times 10^{5}$ to $5 \times 10^{6}$ cells into immunocompetent healthy mice in the experimental tumor model usually results in rapid tumor growth palpable within 2 weeks. Similarly, under clinical setting, rapid mass can be formed after chemotherapy, because formidably large numbers of surviving tumor cells still remain unkilled and patients cannot tolerate any further dosing of chemotherapy. To make the situation worse, a patient's immune system is often greatly suppressed by such treatment that new solid tumor can recur with 
relative ease. Therefore, we still need potent immunostimulating agents that have no side effects like this bamboo extracts. Furthermore, the suppressed immune state is related to a higher incidence of cancer in the aged population, so immunostimulation may be useful for cancer prevention among aged and high-risk populations.

In conclusion, we report here that a dietary supplement of bamboo leaf extracts at a concentration of $0.1 \%$ suppressed solid tumor growth and prolonged the life span in S-180 and C38 models. Such oral administration of the extracts induced Th1-type cytokine production. Also, the extracts stimulated cytotoxic activity of NK cells and macrophages both in vitro and in vivo. These results strongly suggest the great potential of this bamboo leaf extract as an anti-cancer and cancer preventive agent.

\section{Acknowledgements}

We thank Mr Shingo Kikuchi of Cosmobios Ltd Co, Hokkaido, Japan, for supplying samples of bamboo leaf extract, and to Ms Judith B. Gandy to English editing.

\section{References}

1. Shibata M, Yamatake Y, Sakamoto M, Kanamori M, Takagi K. Pharmacological studies on bamboo grass (1): acute toxicity and anti-inflammatory and antiulcerogenic activities of water-soluble fraction (Folin) extracted from Sasa albomarginata Makino et Shibata. Nippon Yakurigaku Zasshi (in Japanese) 1975;71:481-90.

2. Dubois M, Gilles DA, Hamilton JK, Rebers PA, Smith F. Colorimetric method for the determination of sugars and related substances. Anal Chem 1956;28:350-6.

3. Kitagawa T, Tsuboi I, Kimura S, Sasamoto Y. Rapid method for preparing a $\beta$-glucan-specific sensitive fraction from Limulus (Tachipleus tridentatus) amebocyte lysate. J Chromatogr 1991; 567:267-73.

4. Julkunen-Tiitto R. Phenolic constituents in the leaves of northern willows: methods for the analysis of certain phenolics. J Agric Food Chem 1985;33:213-17.

5. Boyum A. Isolation of mononuclear cells and granulocytes from human blood. Isolation of mononuclear cells by one centrifugation, and of granulocytes by combining centrifugation and sedimentation at 1g. Scand J Clin Lab Invest Suppl 1968;97:77-89.

6. Masuda E, Maeda H. Changes in cellular components of spleen and lymph node cells and the effector cells responsible for Meth A tumor eradication induced by zinostatin stimalamer. Cancer Res 1996;56:1868-73.

7. Idani H, Matsuoka J, Yasuda T, Kobayashi K, Tanaka N. Intratumoral injection of doxorubicin (Adriamycin) encapsulated in liposome inhibits tumor growth, prolongs survival time and is not associated with local or systemic side effects. Int $J$ Cancer 2000;88:645-51.
8. Nihei Y, Suga Y, Morinaga Y. A novel combretastatin A-4 derivative, AC-7700, shows marked antitumor activity against advanced solid tumors and orthotopically transplanted tumors. Jpn J Cancer Res 1999;90:1016-25.

9. Matsushita Y, Kumagai H, Yoshimoto A. Antitumor activities of $\left(2^{\prime \prime} \mathrm{R}\right)-4^{\prime}-O$-tetrahydropyranyl-adriamycin (THP) and its combination with other antitumor agents on murine tumors. $J$ Antibiot 1985;38:1408-19.

10. Suzuki F, Suzuki C, Simomura E, Maeda H, Fujii T, Ishida N. Antiviral and interferon-inducing activities of a new peptidomannan, KS-2, extracted from culture mycelia of Lentinus edodes. $J$ Antibiot 1979;32:1336-45.

11. Fujii T, Maeda H, Suzuki F, Ishida N. Isolation and characterization of a new antitumor polysaccharide, KS-2, extracted from culture mycelia of Lentinus edodes. J Antibiot 1978;39:1079-90.

12. Yamashita A, Ohtsuka $\mathrm{H}$, Maeda $\mathrm{H}$. Intestinal absorption and urinary excretion of antitumor peptidomannan KS-2 after oral administration in rats. Immunopharmacology 1983;5:209-20.

13. Hamuro $J$, Rollinghoff $M$, Wagner $H$. Induction of cytotoxic peritoneal exudate cells by $\mathrm{T}$-cell immune adjuvants of the beta (1 leads to 3) glucan-type lentinan and its analogues. Immunology 1980;39:551-9.

14. Tsukagoshi S, Hashimoto Y, Fujii G, Kobayashi H, Nomoto K, Orita K. Krestin (PSK). Cancer Treat Rev 1984;11:131-55.

15. Yoshikawa M, Fujita H, Matoba N, Takenaka Y, Yamamoto T, Yamauchi R, et al. Bioactive peptides derived from food proteins preventing lifestyle-related diseases. BioFactors 2000;12:143-6.

16. Chihara G, Hamuro J, Maeda YY, Arai Y, Fukuoka F. Fractionation and purification of the polysaccharides with marked antitumor activity, especially lentinan, from Lentinus edodes (Berk.) Sing. (an edible mushroom). Cancer Res 1970;30:2776-81.

17. Tabata K, Itoh W, Kojima T, Kawabata S, Misaki A. Ultrasonic degradation of schizophyllan and antitumor polysaccharide produced by Schizophyllum commune FRIES. Carbohydr Res 1981;89:121-35.

18. Kasai H, He LM, Kawamura M, Yang PT, Deng XW, Munkanta M, et al. IL-12 production induced by Agaricus blazei fraction $\mathrm{H}(\mathrm{ABH})$ involves Toll-like receptor (TLR). eCAM 2004;1:259-267;1989;37:410-13.

19. Liu Y, Fukuwatari Y, Okumura K, Takeda K, Ishibashi K, Furukawa $\mathrm{M}$, et al. Immunomodulating activity of agaricus brasiliensis KA21 in Mice and in Human Volunteers. eCAM 2007 Advance Access published on April 12, 2007, doi: 10.1093/ecam/ nem016.

20. Sun AS, Ostadal O, Ryznar V, Dulik I, Dusek J, Vaclavik A, et al. Phase I/II study of stage III and IV non-small cell lung cancer patients taking a specific dietary supplement. Nutr Cancer 1999;34:62-9.

21. Sun AS, Yeh HC, Wang LH, Huang YP, Maeda H, Pivazyan A, et al. Pilot study of a specific dietary supplement in tumor-bearing mice and in stage IIIB and IV non-small cell lung cancer patients. Nutr Cancer 2001;39:85-95.

22. Murakami H, Yamafuji K. Antitumor activity of lignin. Sci Bull Facul Agr Kyushu Univ 1968;23:103-11.

23. Iio M, Yamafuji K. Antitumor activity of bamboo-leaf polysaccharide. Sci Bull Facul Agr Kyushu Univ 1968;23:113-18.

Received September 24, 2007; accepted March 20, 2008 


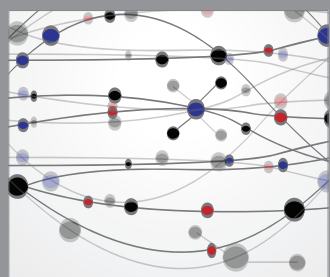

The Scientific World Journal
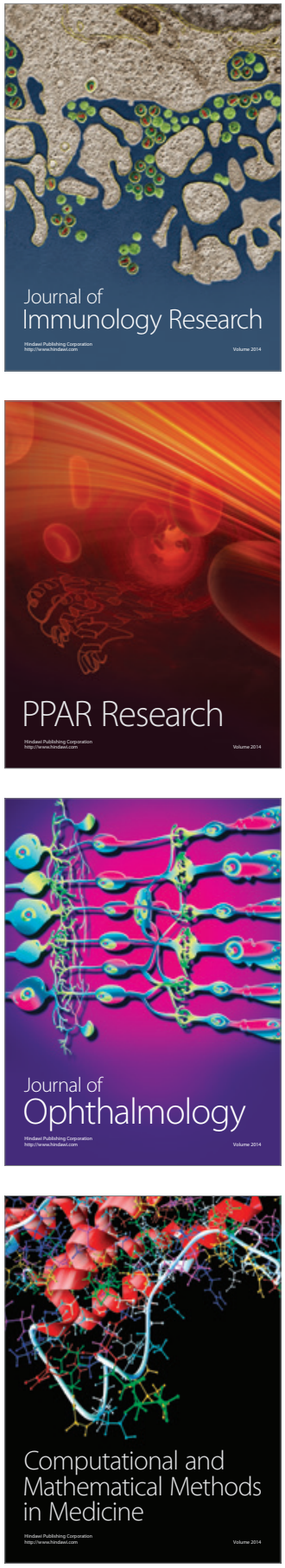

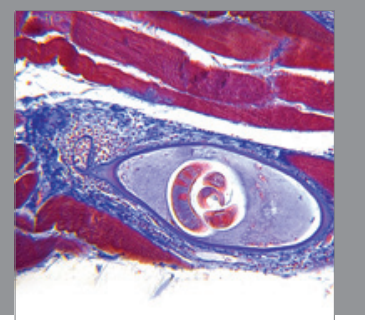

Gastroenterology

Research and Practice
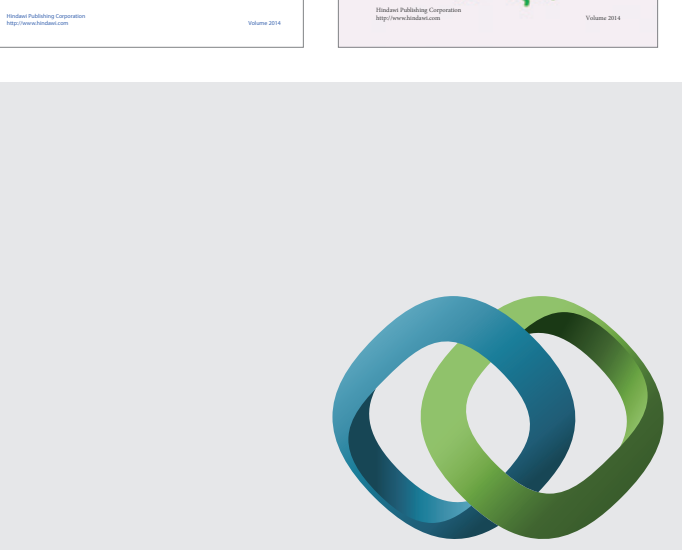

\section{Hindawi}

Submit your manuscripts at

http://www.hindawi.com
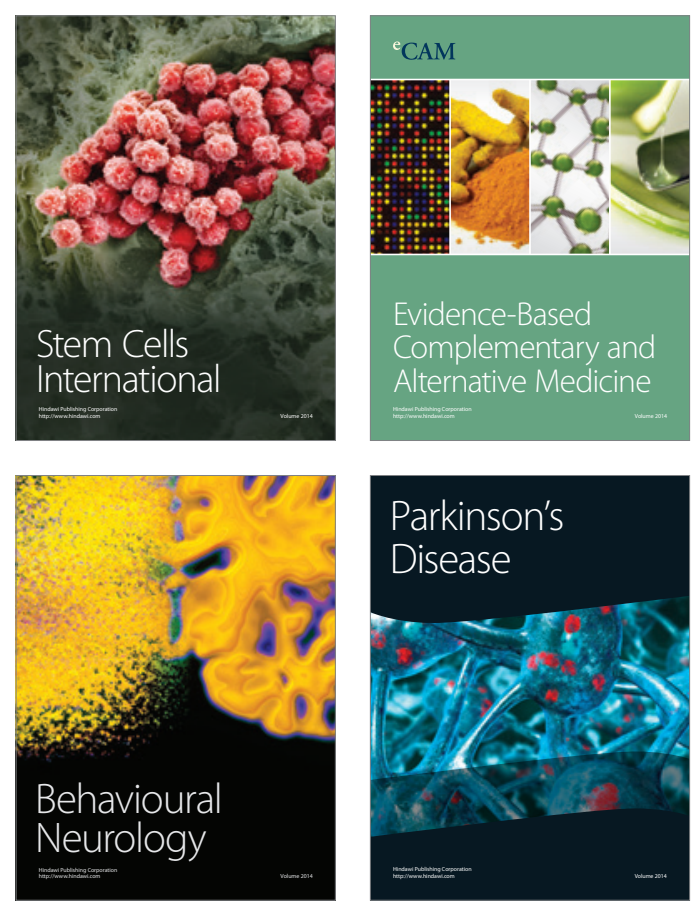

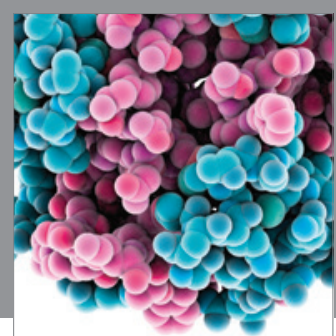

Journal of
Diabetes Research

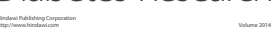

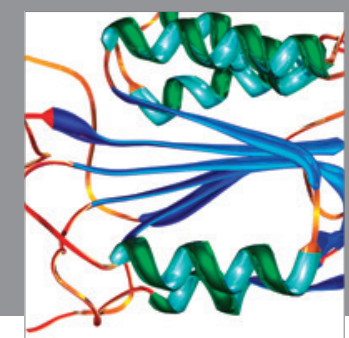

Disease Markers
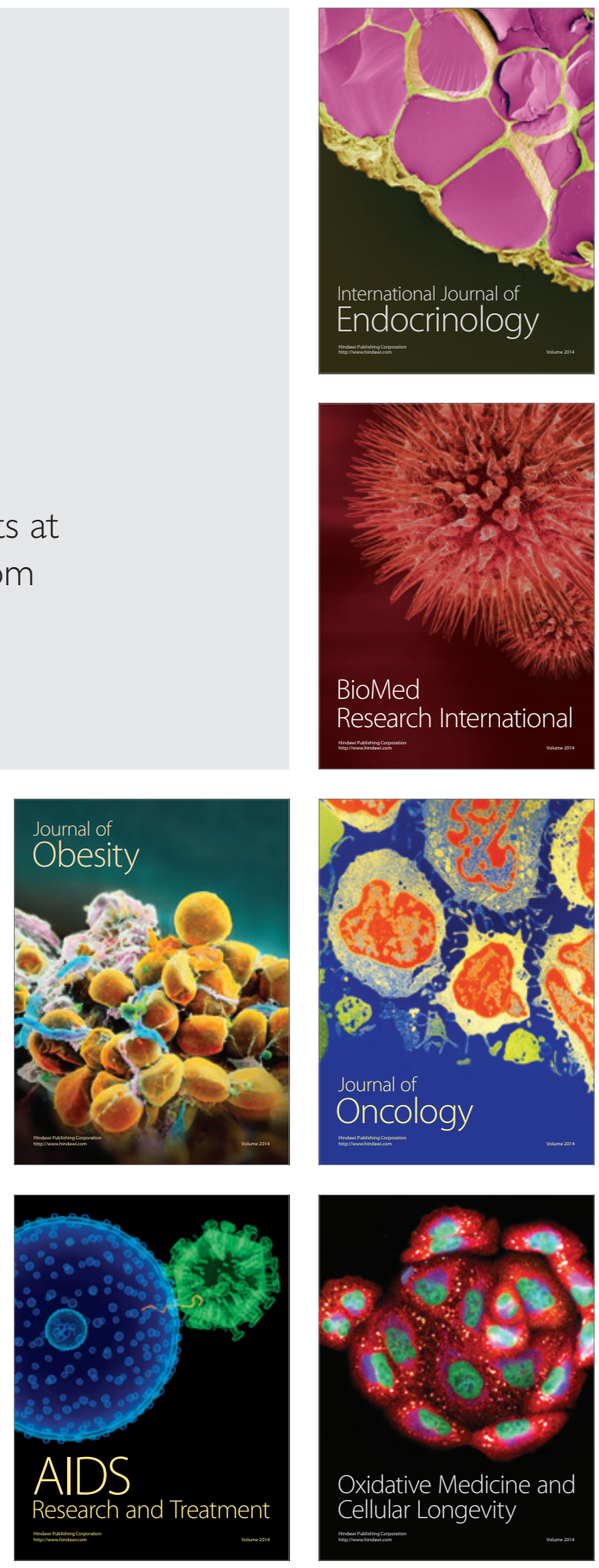